\title{
Computer Graphics in Lighting Engineering Education: Teaching Photometry and the Basics of the Light Field
}

\author{
Vladimir Budak ${ }^{1}$ and Denis Makarov ${ }^{2}$ \\ ${ }^{1}$ National Research University "MPEI", Krasnokazarmennaya st., 14, Moscow, 111250, Russia \\ ${ }^{2}$ Lighting engineering company LLC "Vidno", Moscow, 111622, Russia
}

\begin{abstract}
The modern level of computer graphics programs (CGP) has long been able to solve most design, architecture, and lighting design problems. However, the use of CGP in teaching students is still underestimated. The existing traditional teaching methods cannot effectively teach the basics of lighting engineering and photometry to students. This is especially true for the concepts of illumination that are difficult to understand - luminance (radiance), color temperature. The article offers a method of teaching photometry based on the wide use of CGP. Within the methodology framework, 3D laboratories were developed. Students can study the basics of lighting engineering and optical effects, visually observe most lighting quantities, see their relationship, and interact with the surrounding space and objects. More than ten 3D training models on interior, architectural, and road lighting have been modeled. Within each model, students are given tasks for independent work. Checking the received material from students at several leading Russian universities allowed us to conclude on the methodology's effectiveness and outline many key aspects of its development.
\end{abstract}

Keywords

Lighting design, light engineering, 3D modeling, lighting modeling, education

\section{Introduction}

This article continues our research in developing a unified methodology for teaching light design in engineering and art education [1,2]. Recall that the basis of the proposed teaching method is the rejection of the traditional method of dividing teaching into lectures, seminars, and laboratory work favoring masterclasses based on modern computer graphics programs (CGP), such as DIALux and DIALux evo [3]. At the same time, the study of theoretical material is based on the demonstration of quantities and laws in computer models. After that, students receive an individual task on using the studied material on specific lighting installations. The use of computer models in the design of interior and exterior lighting has become an international standard for lighting design today. The images of scene objects obtained because of modeling in combination with numerous light distribution analysis tools make it possible to obtain both quantitative lighting indicators (illumination, brightness) and qualitative ones: an indicator of discomfort, unevenness, light rhythm, contrast, etc. The correct use of CGP allows taking an important place in students' training programs in architectural and art universities. The primary role in these universities is the education of the "sense of light" in students [4] and the use of light as an artistic tool closely and inextricably linked with visual and emotional perception.

Currently, there are many educational programs in the field of light design in Europe [5, 6]. It is worth noting that they are interdisciplinary and usually cover three disciplines in which light is used: architecture design, lighting engineering, and media technologies. In many months of training, students receive much visual information on disciplines, and synthetic 3D models, images, and multimedia software complexes play an essential role in this. As a result of the training, students should integrate

GraphiCon 2021: 31st International Conference on Computer Graphics and Vision, September 27-30, 2021, Nizhny Novgorod, Russia EMAIL: budakvp@gmail.com (V. Budak); makarovd@list.ru (D. Makarov) ORCID: 0000-0003-4750-0160 (V. Budak); 0000-0002-5043-8911 (D. Makarov)

(c) (i) (C) 2021 Copyright for this paper by its authors.

(C) 2021 Copyright for this paper by is authors.

CEUR Workshop Proceedings (CEUR-WS.org) 
the acquired knowledge in three areas, create creative lighting installations, and perform technical, aesthetic, and environmental norms and rules [7].

The primary purpose of this work is to develop a teaching methodology for students in the direction of light design based on the visual and practical application of computer graphics programs. A unified approach to forming lighting design and lighting engineering in training is proposed through thematic master classes on specially designed 3D models in the CGP.

In engineering education, the use of CPG is significantly higher than in the humanities, but, in our opinion, their applied value is far from being disclosed. The existing methods of teaching light design in engineering universities offer students to learn the "basics of lighting engineering" in the form of a set of fundamental formulas, laws, mathematical and physical relationships of the main light quantities, such as luminous flux, luminous intensity, illumination, luminance, exposure, the law of inverse squares of distance and much more. It is self-evident that knowledge of the fundamental foundations of the science of light is necessary. Still, as our observations show, without practical and visual demonstrations, actions, influences, and interactions of light in space with objects, the assimilation of knowledge is weak and requires many years of experience.

In the modern world with a vast information flow, when practical skills play an increasingly important role, it is not enough to show conditional drawings, sketches, and show photos of completed projects to teach a student to think, create and invent something new, creating high-quality lighting installations. It is required to immerse the student in the process of modeling lighting of different types. Only then, by trial and error, applying theoretical knowledge, the student will master the fundamental practices of lighting design in a short time, not only master the material but also learn to think [8].

One of the solutions to this problem can be a lighting laboratory with an actual demonstration of lighting devices (SP) and optical measuring instruments. Such laboratories exist in engineering universities and private companies. Despite this, there is an understandable and well-known limitation in the material support of such laboratories. To demonstrate a particular lighting effect or approach in lighting and explain the nuances of the light environment or light accents, it is necessary to organize a special seminar, the personal presence of listeners, the allocation of human information, and material resources. In addition, it is necessary to consider the forced restrictions of the modern world on holding mass events because of COVID-19. All this creates conditions under which the systematic participation and holding of such seminars are possible only for a limited number of listeners.

Our methodology offers students to solve lighting engineering and lighting design problems without getting up from their workplace. Naturally, the authors are aware of the importance of the relationship between the teacher and the student and the practical experience of the relationship with real SP and measuring devices. We also understand the difference between synthetic images on the screen with the distribution of brightness in the observer's field of view in the natural environment. However, the authors are deeply convinced that up to $80 \%$ of the lighting engineering and lighting design problems can be qualitatively demonstrated and solved with the help of the correct application of CGP.

This article is devoted to teaching light field theory and photometry basics to design students and engineering students.

\section{Improvements to the methodology}

Over the past year, we have improved our training methodology based on CGP use in two main areas. The authors have developed computer models of rooms and models of 3D light laboratories for conducting classes and experiments. It is possible to work with light values, color, visual effects, and calculated parameters. It becomes possible to demonstrate such light effects visually and with the highest possible accuracy (Fig. 1):

- the distribution of illumination in the volume from the light source model simulating one or more candles. Thus, the relationship of the luminous flux $(F)$ with the luminous intensity $(I)$ and the created illumination $(E)$ is demonstrated;

- the distribution of illumination (luminance) on an arbitrary surface from the light device (LD) with different light intensity curves (LIC). By changing the luminous flux or electrical power (P) of the LD and changing the distance away from the surface, students learn to understand the relationship between $(F, P, I, E)$ and distance; 
- evidently modeled conditions showing the fulfillment of the law of squares of distance, the change in illumination from a distance;

- $\quad$ the visual perception of various values of the correlated color temperature $\left(T_{c}\right)$ from $3000 \mathrm{~K}$ to $6800 \mathrm{~K}$ is represented as light beams of LD with one type of LIC. Students learn to illuminate objects with different colors using one or another shopping center and conclude improving or worsening the resulting color perception;

- modeling of situations in which the illumination values $(E)$ are performed, but when conducting an in-depth analysis of the calculated light parameters: luminance ( $L$ ), discomfort indicator (UGR), it becomes clear that the lighting installation is not working correctly;

- Identification of dependencies between $F, E, L$ when changing $T_{c}$, while students are forced to use the ray-tracing method and choose the parameters of the best lighting solution;

- modeling of light and shadow - a classic example of lighting geometric primitives with different $\mathrm{LD}$ with different light and energy parameters $(F, I, P)$ teaches students to understand the shape changes and the perception of the volume of objects when illuminated;

- demonstration of the work of colored light and additive color mixing (RGB). Students are invited to obtain the purest resulting white light by selecting the luminous flux $F$ of each of the three spotlights located next to each other.
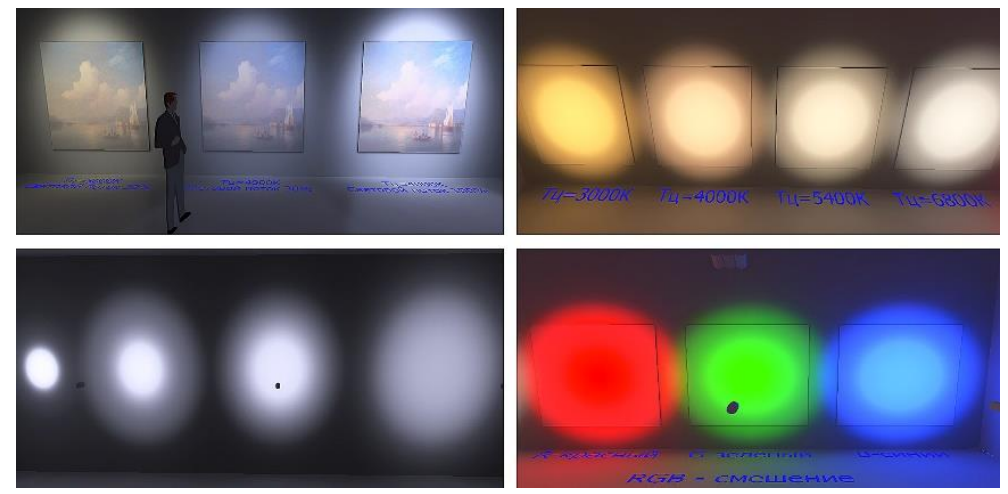

Figure 1: Image 3D light laboratories of some lighting effects in DIALux evo.

Currently, the methodology includes nine laboratory works:

1. Introductory laboratory work-the basics of working in DIALux evo;

2. 3D light laboratory for explaining and demonstrating the main lighting effects of lighting;

3. classroom lighting;

4. light in the museum;

5. office space lighting;

6. clothing store lighting;

7. car dealership lighting;

8. road lighting;

9. architectural lighting.

The principle of choosing lighting objects (models) and the learning style inherent in them adhere to the "Step by step" principle, so students, performing various tasks on different models, from simple to complex, learn and gain comprehensive knowledge in the field of lighting design.

\section{Examples of training models}

Here we offer a brief review of several training models we have created to give a general impression of our work.

Let us start with the "introductory laboratory work." The main task for students is to master the basic principles of working with the DIALux evo program and acquire the skills they will need in subsequent laboratory work.

In laboratory work, students are invited to make a 3D model of a living room themselves in three stages (Fig. 2). The first stage is the construction of the geometry of the room. The second stage is the 
installation of furniture objects, windows, and doors. The third stage is reduced to assigning materials to the room's surfaces and furniture with the necessary textures. Then the fourth stage is the selection and installation of lamps. Students are invited to either choose a joint venture from a basic already prepared set or with the help of specific procedures to find and use lamps to their taste. The last fifth stage - the analysis of lighting, is the most important and allows students to assess the correctness of the choice and installation of a joint venture within the framework of regulatory requirements. If the requirements are not met, the student is obliged to go back to one stage. As a result of the laboratory work, the user is given a detailed description of the necessary actions and is offered the freedom to choose various architectural and lighting parameters and objects. As a result, we get different projects of rooms, including their different lighting and analysis.

In another laboratory work, in the second half of the course- "car dealership lighting," students are offered an entirely constructed 3D car dealership building with architecture, placed cars, and even test lamps (Fig. 3). The main task of users is to create correct, meeting lighting requirements for all areas of a 2-story improvised car dealership. The building has characteristically pronounced functional areas - a showroom, a reception, a recreation area, managers ' work areas, a delivery area, etc.

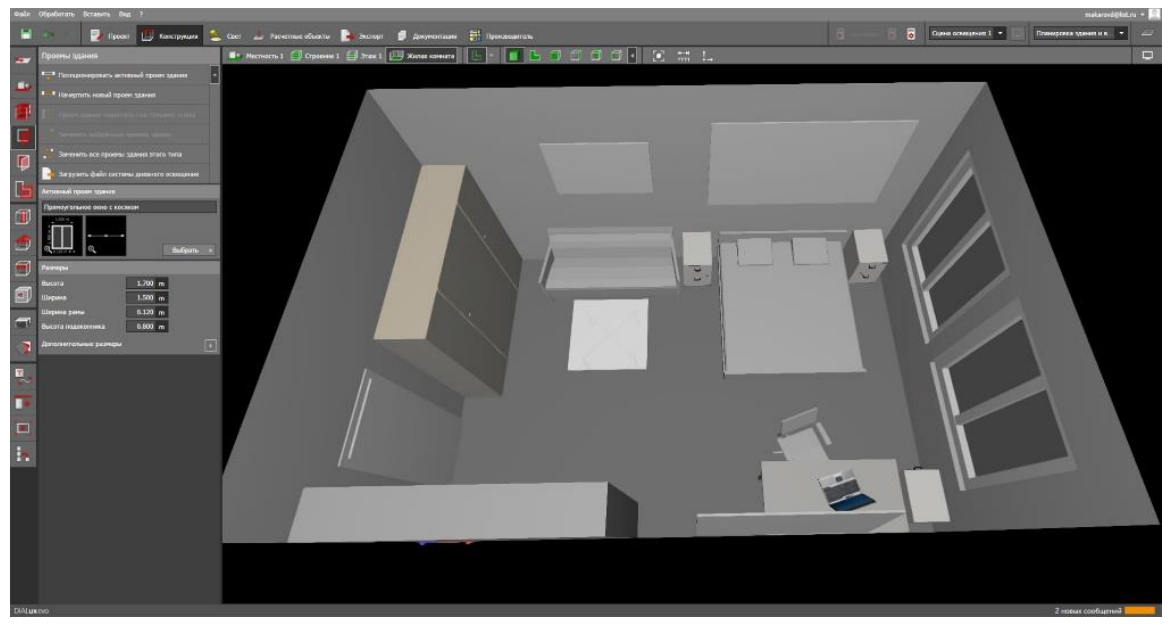

Figure 2: 3D model of the room in DIALux evo - each student creates his model, but if, for some reason, he fails, he can always use this ready-made model.

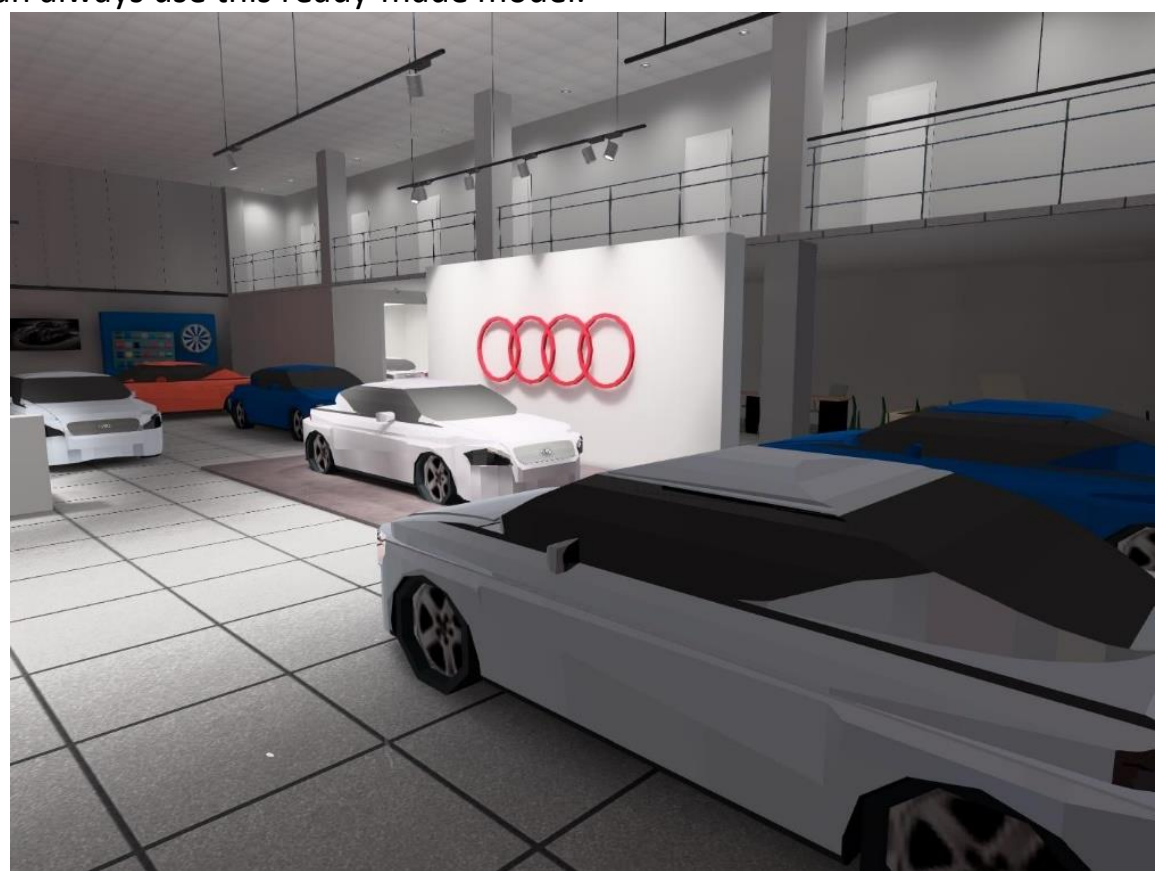

Figure 3: 3D model of a car dealership in DIALux evo - test light: the ray-tracing method is used.

All these zones require individual lighting and achieving their own lighting indicators. Still, the task is also complicated because all these zones are in the same architectural space. The light designer must 
find a balance between joint ventures' right choice, location, architecture, lighting indicators, and lighting design with a complete imitation of the switched-on light in all areas of the car dealership. It is important to note that it will be difficult or even impossible for students to complete this task if, for some reason, they did not complete or missed the previous six laboratory classes. The task for this laboratory work is to conduct a light analysis of all areas of the car center and numerical proof that future customers and their employees will be as comfortable as possible. An additional task is creating photorealistic images using ray tracing, which should prove that the visual perception of the car dealership is fulfilled in the requirements and is harmonious.

The following laboratory work, which we will briefly consider, will be "road lighting." Its peculiarity lies in the fact that to solve the tasks set in it. It is required to use another CGP, namely the free-ofcharge distributed lighting program Light-in-Night Road (LiN) [9], developed by Russian engineers. The proposed task in the laboratory work is exciting since it offers future light designers not only to master a new CGP for them. They must also design lighting for an arbitrary street consisting of a twolane road, pedestrian paths surrounded by residential buildings (Fig. 4). The 3D model is already issued to students in a ready-made form, with street lighting poles and lamps placed, but with obsolete ones. The task is to choose from the existing database of modern LED (LED) lamps such that it would be possible to replace the old ones effectively. As a result of the work, it is proposed to change most of the parameters of the lighting system. The main thing, in the end, is to obtain and prove the legality and economic efficiency of such a replacement.

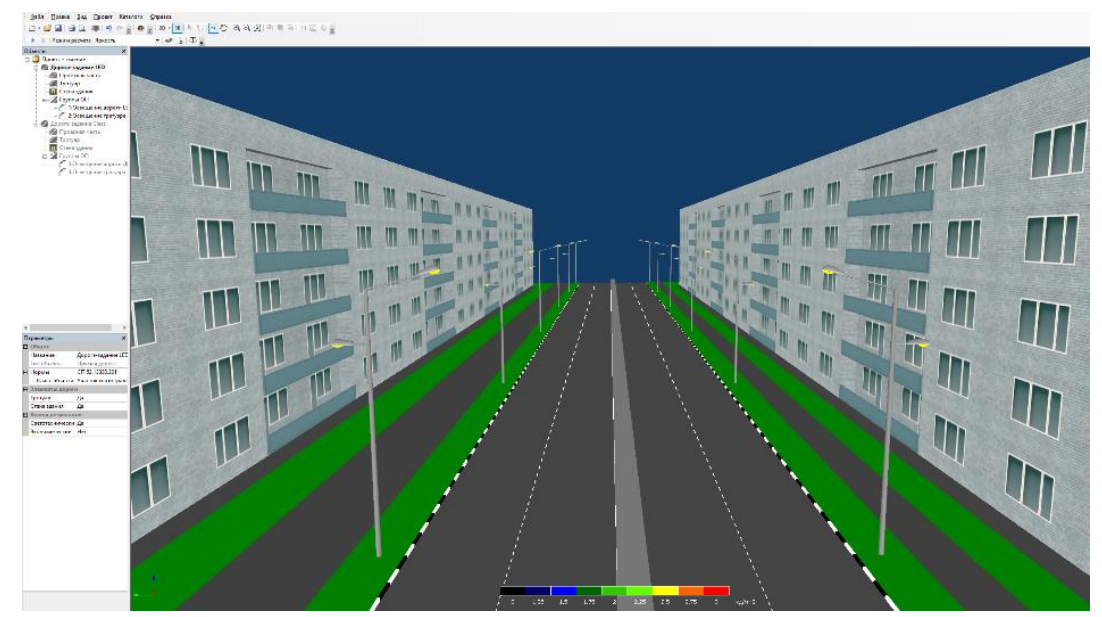

Figure 4: General view of the program (LiN). 3D model of the road with spaced supports and lamps.

The final topic of our course is laboratory work- "architectural lighting." From the name itself, it can be understood that students are invited to conduct a simulation of architectural lighting of a building in the classical style (Fig. 5).

The model is also wholly transferred to perform the work. Still, it is impossible to perform the correct architectural lighting that meets the norms and rules without a detailed analysis of the types of lighting, existing types of the joint venture, and the lighting environment and lighting installation requirements. In this regard, an additional explanatory seminar is held in this work primarily before completing the lighting task.

The model already includes more than eight types of joint ventures for architectural lighting. Students are encouraged to use them or any other suitable for modeling architectural lighting of a building. It is important to note that it is possible to change all the parameters of the joint venture and the 3D model according to the task. Still, as a result, the contractor is also required to comply with all the necessary regulatory requirements. 


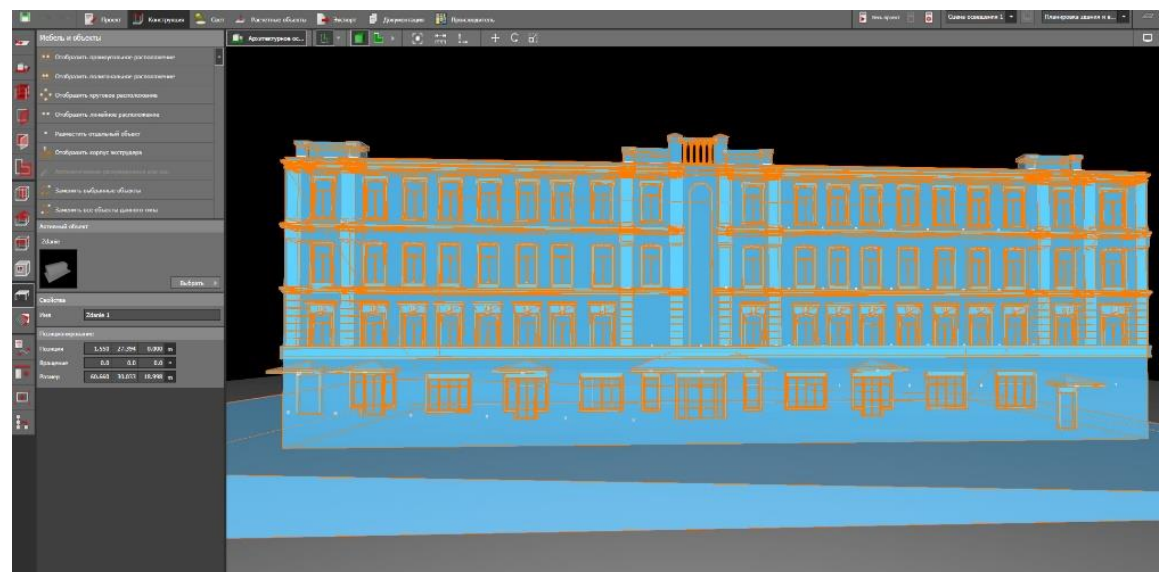

Figure 5: View of the building in the DIALux evo program. Preparation for the placement of luminaires.

\section{Conclusions}

Our proposed method of teaching students based on CGP has been assessed by engineers and designers of the Department of Lighting Engineering of the "NRU "MPEI" and designers of the Stroganov Moscow State Academy of Arts and Industry and "NRTU "MISiS" the Department of Computer-aided and Art Design. The following results were obtained:

- $\quad$ starting from the second and third classes, there is a noticeable increase in the assimilation of fundamental lighting concepts, and greater meaningfulness of actions in the design is manifested;

- $\quad$ by the end of the course, students show imagination and creativity. The fear of making mistakes disappears, and a sense of freedom - creation is manifested while within the established norms and rules;

- $\quad$ according to the results of the classes, the authors were convinced that conducting a course according to the proposed methodology on synthetic models, before practical work with real SP and measuring instruments, gives a significant increase in the educational effect.

It should be noted that a comparison was made with the training of students according to the classical methodology. This comparison showed that the training of a specialist of the same qualification according to the new method could be achieved in half the training period. Thus, we are convinced that the further development of this methodology, based on CGP, will lay the foundation for creating a single-specialty - lighting design.

\section{References}

[1] V. Budak, D. Makarov, Computer Graphics: New Horizons in the Education of Lighting Designers and Engineers, CEUR Workshop Proceedings 2744 (2020), short43-1 - short43-7. doi: 10.51130/graphicon-2020-2-4-43.

[2] V.P. Budak, M.D. Kovyrkova, D.N. Makarov, S.Yu. Minaeva, A.A. Skornyakova, Lighting design: education of creative abilities among lighting engineering students, Svetotekhnika 1 (2019) 80-83. (in Russian)

[3] In-service training at DIAL: DIALux, Lighting, Smart Building, 2021. URL: https://www.dial.de/en/training/

[4] N.V. Bystryantseva, E.Yu. Lekus, I.S. Smilga, D.A. Chirimisina, V.V. Lukinskaya, Retrospective of the discipline "Principles and methods of light modeling" within the framework of the direction of light design, Modern problems of science and education (Sovremennye probledmy nauki I obrazovaniya) 2 (2020). doi: 10.17513/spno.29688 (in Russian)

[5] The MSC programme, Aalborg University, 2021. URL: https://www.light.aau.dk/msc-education

[6] Professional studies master program lighting design. Wismar University, 2021. URL: https://studieren.de/fileadmin/europe/germany/_study/docs/Master_Lighting_Design.pdf

[7] Environmentally Conscious Smart Lighting (ECOSLIGHT Project), 2021. 
URL: http://www.ecoslight.eu

[8] A.V. Bulatova, The development of creativity among designers and specialists in advertising in the process of studying at a university, in: All-Russian Scientific Conference. Ekaterinburg: Ural Fed. Uni., Vol. 1, 2014, pp. 534-537. (in Russian)

[9] Light-in-Night Road, 2021.URL: http://www.light-in-night.com 